University of Nebraska - Lincoln

DigitalCommons@University of Nebraska - Lincoln

Publications from USDA-ARS / UNL Faculty

U.S. Department of Agriculture: Agricultural

Research Service, Lincoln, Nebraska

2008

History and Ecological Basis for Areawide Pest Management

Norman C. Elliott

United States Department of Agriculture-Agricultural Research Service, norman.elliott@ars.usda.gov

David W. Onstad

University of Illinois at Urbana-Champaign

Michael J. Brewer

Michigan State University, michael.j.brewer@noaa.gov

Follow this and additional works at: https://digitalcommons.unl.edu/usdaarsfacpub

Part of the Agricultural Science Commons

Elliott, Norman C.; Onstad, David W.; and Brewer, Michael J., "History and Ecological Basis for Areawide Pest Management" (2008). Publications from USDA-ARS / UNL Faculty. 646.

https://digitalcommons.unl.edu/usdaarsfacpub/646

This Article is brought to you for free and open access by the U.S. Department of Agriculture: Agricultural Research Service, Lincoln, Nebraska at DigitalCommons@University of Nebraska - Lincoln. It has been accepted for inclusion in Publications from USDA-ARS / UNL Faculty by an authorized administrator of DigitalCommons@University of Nebraska - Lincoln. 


\title{
History and Ecological Basis for Areawide Pest Management
}

\author{
NORMAN C. ELLIOTT, ${ }^{1}$ DAVID W. ONSTAD ${ }^{2}$ AND \\ MICHAEL J. BREWER ${ }^{3}$
}

${ }^{1}$ US Department of Agriculture, Agricultural Research Service, Plant

Science Research Laboratory, Stillwater, Oklahoma, USA; '2 National

Soybean Research Center, University of Illinois, Urbana, Illinois, USA;

3 Integrated Pest Management Program, Department of Entomology,

Michigan State University, East Lansing, Michigan, USA

\section{Introduction}

The traditional approach to pest management is to treat the crop or commodity in a particular management unit before an economically significant infestation of the pest has developed. Determining the need to take corrective action is based on the economic threshold concept, which forms the basis of most integrated pest management programmes (Metcalf and Luckman, 1975). Areawide pest management (AWPM) can be contrasted with traditional pest management in that pest management tactics are used over a broad spatial area, often treating the whole area simultaneously to maintain the pest below economic levels or, in some cases, completely eradicate it. AWPM has potential advantages over the traditional approach. Suppression across a broad area may result in reduced reinfestation by migration from nearby unmanaged areas, and the pest management tactics employed may be more effective, particularly ecologically based tactics, when applied areawide.

A diversity of approaches exists for AWPM. The strategies used in programmes obviously must be based on the particular species that is the target of the management effort. Detailed understanding of the pest's biology and ecology, the ecological system as a whole and the pest management tactic(s) available for deployment will provide insight into the most promising avenues for effective suppression over a broad spatial area. While virtually any pest of humans or their enterprises, agricultural or otherwise, can be a target of AWPM, we will focus on AWPM of insect pests of agriculture in this chapter. The concepts are applicable to weeds and other non-insect pests, and to non-agricultural pest problems.

Dr Edward F. Knipling was among the first to formalize the idea that use of preventive approaches for managing pests on an areawide basis could be more effective and less environmentally detrimental than curative approaches, which often rely on repeated use of insecticides on individual fields (Klassen, 2003). Preventive approaches fall into two 
basic categories: those that make the particular management unit more resistant to pest attack and those that reduce the likelihood of attack in the first place. AWPM programmes have used both approaches, but usually rely more heavily on the second.

In most cases hosts that can serve as reservoirs for a particular pest exist outside of the managed ecosystem, from which the pest can colonize it via dispersal or migration. Knipling recognized this and considered lack of control in unmanaged ecosystems and lack of synchronous control across ecosystems as the main reasons pest populations were not being effectively controlled by management applied on an individual field basis. Knipling's (1992) principle formalized that idea when he wrote: 'Uniform suppressive pressure applied against the total population of the pest over a period of generations will achieve greater suppression than a higher level of suppression on most, but not all, of the population each generation'. Total population refers to the sum total of individuals of the species in a defined area as opposed to just those occupying a particular crop or other commodity in need of protection. Usually, the area defined for the total population is one that has the geographic integrity such that the population within it is more or less geographically isolated from other populations of the species. Knipling (1992) asserted that, in order for major advances to be made in managing many important pest problems, strategies and tactics for managing pests would need to change from the curative approaches targeting the pest on the protected crop to strategies based on suppressive measures targeting the total population preventively.

Knipling spent most of his career on eradication programmes for pests rather than on AWPM per se, but the two approaches have much in common, the major difference being the ultimate goal - areawide extermination versus suppression and maintenance at non-economic levels. Both centre on environmentally sound tactics that, when applied over a broad geographic area, can eradicate the total pest population or, in the case of AWPM, maintain it at non-economic levels. The difference between the two strategies is that eradication requires an intensive effort over a broad enough geographic area such that there is no possibility for migration by the pest into the suppression area over a reasonably long time horizon. This means that for eradication to be successful the suppression area must be effectively isolated from areas where migrants could enter and that the pest management tactics applied exert mortality much greater than the pest's reproductive capacity. These tactics must be applied within the suppression area on a frequent enough basis to maintain the population on a downward trajectory until eradication is eventually achieved. Whether or not tactics need to be applied synchronously over the entire area for the duration of the programme is arguable because some effective programmes, e.g. the boll weevil eradication programme, have focused on treating only 'hot spots' after an initial, brief phase of synchronous suppression.

\section{A Brief History and the Development of AWPM}

Klassen (2000) gives a very interesting account of the history of AWPM, which we shall recount here only briefly. Klassen notes that AWPM approaches are not new, and that early civilizations probably worked cooperatively to control pest invasions, 
such as those by armyworms and locusts, at scales greater than a single landholding. For example, in China an AWPM programme for the migratory locust, Locusta migratoria maniensis, has evolved as the result of over 3000 years of experience with periodic outbreaks along the flood plains of some major rivers. The AWPM programme for the locust now has a firm scientific basis and uses modern pest forecasting and management tools, but was initiated long before the advent of the modern scientific method, and based mainly on application of cultural practices and water management along major waterways that prior experience had shown were effective as preventive tactics to control the pest (Metcalf, 1991). Klassen (2000) discusses several additional early examples of use of the AWPM approach that grew out of practical necessity and experience with the particular pest.

Understanding of the biology and ecology of many highly mobile pests of agriculture is improving, as are the technologies for suppressing pest populations. The majority of modern-day programmes that can be classified as AWPM rely on a limited number of tactics targeted at distinctive characteristics of the pest insect's biology or ecology, most notably the sterile insect technique used in eradication programmes for the screwworm, fruit flies and other insects. Use of broad-spectrum insecticides for broad-scale suppression of mosquitoes and other pests can also be classified as an areawide approach (see Tan, 2000 for more examples). Few tactics specifically for use in AWPM exist, partially because limited emphasis has been placed on developing the AWPM concept within educational and research institutions. The expense and lack of funding available for such research has historically been a limiting factor (Linquist, 2000), but many current strategies for deploying existing host plant resistance, cultural control and biological control may be adaptable to, and benefit from, a more concerted effort in areawide deployment.

During the last decade, implementation of AWPM in the USA has been enhanced by the US Department of Agriculture, Agricultural Research Serviceadministered Areawide Pest Management Program (Calkins and Faust, 2003), and examples of AWPM implementation using a broader array of approaches and tactics now exist. A major goal of this book is to overview the AWPM programmes that have been implemented recently, to highlight the diversity of pests addressed by the AWPM approach and the various tactics used in the programmes.

One potential drawback to the AWPM approach is the need to coordinate the programme with stakeholders, sometimes with diverse interests. Achieving stakeholder buy-in to the potentially highly regimented and expensive programmes used in AWPM requires the pest not only to be a serious economic detriment to the commodity, but also to be consistently present at economic levels. Otherwise, the sustained sense of urgency needed to motivate stakeholders to support the programme will be difficult to achieve. Even then, it may be difficult to maintain support for the programme over the long term once the pest becomes non-significant economically and stakeholders focus on more immediately pressing issues.

For some pests it may not be feasible to undertake eradication, because these criteria cannot be met, the cost of the programme exceeds the benefits, the economic resources required are unavailable or the political will needed to initiate such a programme cannot be generated and sustained. The policy and institutional issues involved in developing and sustaining AWPM programmes are discussed in detail in later chapters of this volume. For the remainder of this chapter we will focus on 
ecological issues relevant to AWPM. Our objective is to highlight the role that recent advances in the study and understanding of spatial interactions in biological populations might play in optimizing AWPM approaches for pests.

\section{Ecological Theory and Models Supporting AWPM}

Optimizing an AWPM programme to maximize the suppression achieved and minimize the cost incurred would enhance the potential for success. One obvious limitation to optimal application of the total population management concept advocated by Knipling for many pests is lack of sufficient knowledge of the biology and ecology to establish the spatial extent of the total population to be managed. The total population could be as large as the geographic range of the species, or as small as a single field.

Even though AWPM was originally based on the concept of synchronous and uniform control of the total population of a pest, it has been implemented in a wide variety of ways over space and time. Management strategies may synchronize control over only part of a region infested by a pest at a time, for example by eradicating it from one edge to another; or control may be synchronized over patches and subpopulations, and not the 'total' population, when permission cannot be obtained from all public and private landholders. Lack of synchrony is exemplified by the boll weevil AWPM programme in the southern USA, where the spatial strategies for management were applied at various locations and times for a variety of logistical and political reasons. Thus, an ideal AWPM plan may only rarely be implemented in practice.

Recent advances in ecological theory have much to contribute to development of the AWPM approach. For example, Levins' (1969) classic work on metapopulation dynamics, while receiving interest predominantly from conservation biologists, was originally proposed as an explanation of the dynamics of pests existing in spatially structured populations. Since populations of most species, especially pest species, have broad spatial distributions with some degree of population subdivision, metapopulation theory may be useful for understanding population dynamics of pest species and designing effective AWPM programmes. Recent advances in landscape ecology emphasizing spatial interactions among populations (Pickett and Cadenasso, 1995) may also contribute to AWPM. Simulation modelling is obviously an important tool for understanding the dynamics of complex systems, such as populations existing in spatially heterogeneous landscapes. Next, we will focus on some spatial ecology, modelling and monitoring concepts as they relate to defining and optimizing AWPM programmes.

\section{Temporal and Spatial Scales in AWPM Strategies}

Some ecologists have expressed concern about the lack of consideration of temporal and spatial scales in ecological hypotheses (Levandowsky and White, 1977; Allen, 1989). Often, claims are made and conclusions drawn about the conditions that promote or inhibit the AWPM of arthropods without the operational temporal and spatial scales being specified. Without scales for example, we do not know whether a given concept pertains to $1 \mathrm{~m}^{2}$ and 1 day or to 1 million $\mathrm{km}^{2}$ and 1 year. 
If management strategies are to be tested and implemented, we need to strive for more precise concepts that include general temporal and spatial scales for which the concepts are valid. Onstad (1992) evaluated this problem in epidemiology and proposed criteria for identifying appropriate scales and definitions of important terms. Criteria for identifying temporal and spatial scales should be based on consistency of observation and ecological validity. Scales must account for behaviour and longevity of the targeted pest. Temporal and spatial units must correspond, for logical reasons.

The minimum time unit for analysis of management is likely to be the generation time for the targeted arthropod. When control is synchronized for AWPM, it is likely to be synchronized by generation and not calendar time. Onstad (1992) discusses the various ways of measuring generation time for arthropods with discrete or overlapping generations. The minimum spatial unit should be the two- or threedimensional space that is traversed on average by the targeted arthropod during a generation. The ecologically proper spatial scale depends upon a species' biology and behaviour, and must be large enough to encompass all normal movement by the average individual (Weins, 1976; Addicott et al., 1987). For example, Schneider (1989) considered the temporal and spatial scales and experimental designs for field experiments needed to evaluate AWPM. Schneider (1989) concluded that two small areas could be studied for 6 years, or two larger areas could be evaluated for 2 years, to determine the feasibility of an AWPM approach.

The spatial and temporal context of the AWPM strategy should be declared. The time horizon is the term used to describe the period over which the management occurs. Every model, of course, has a time horizon for its analysis. Because of the variable nature of ecological systems in space and time, the ecological conditions on which management depends may not be valid after a certain number of arthropod generations, or when a very large number of minimum spatial units are considered together. For eradication, it is clear that the total population must be defined to include a geographic area of sufficient extent to preclude recolonization of the eradication zone over a relatively long time horizon. For areawide suppression programmes there are no similarly obvious guidelines. Obviously, the maximum spatial extent should not exceed the existing area inhabited by a species, but best estimations are needed on whether infested fringe areas that are never managed should be included within conceptual spatial boundaries of a suppression zone.

Commonly, practitioners of AWPM define boundaries of a suppression area based on a mix of biological, economic, political, sociological and other criteria (Klassen, 2000; Linquist, 2000). The 'what and where' in regard to the total population is an elusive question, but certainly should be entertained by AWPM researchers and practitioners. A metapopulation or landscape perspective may be helpful in defining ecologically optimal scales for application of AWPM programmes for particular pests. We will explore those concepts with respect to AWPM in the following sections.

\section{Metapopulation Ecology and AWPM}

Metapopulation ecology is one approach to the study of spatially structured populations. The basic assumption of Levins' (1969) metapopulation dynamics concept and 
subsequent refinements is that the environment is heterogeneous. This heterogeneity can be partitioned into discrete patches suitable for inhabitation by the species that are distinguishable from everything else that is considered uninhabitable. Thus, suitable habitat for a species occurs as a network of patches distributed in space and embedded in a matrix of non-suitable areas (see Fig. 2.1a). The matrix is not explicitly considered in the metapopulation approach and is assumed to be neutral in terms of its effect on population dynamics, apart from that of separating patches of suitable habitat.

Habitat patches can vary in size and quality and differ in many attributes important to a particular species. The metapopulation approach also assumes that patches are small enough that the resident populations are more or less panmictic, but far enough apart that migration between patches is an occasional event (Hanski and Gilpin, 1997).

Most insects of pest management concern are highly mobile and migratory according to the definition of Drake and Gatehouse (1994), and it might seem that the metapopulation concept would provide limited insight on effective AWPM strategies beyond that achieved by considering the total population as a panmictic unit. However, Murphy et al. (1990) argue that the metapopulation approach is particularly applicable for small organisms with high population growth rates that have specialized habitat requirements, traits that are exhibited by many pest species.

Migration in insects usually takes place during a single life stage, and often for only a short time; during other life stages individuals are more or less restricted to a single patch of habitat. Thus, migration is a more or less discrete event within a generation for many pest insects. Furthermore, even though agricultural crops are grown extensively in some areas, they still occur as discrete patches within a heterogeneous matrix composed of patches that may or may not be suitable for inhabitation. Byrne (Chapter 4, this volume) discusses the critical role that migration plays in the ecology of pests and in determining pest status and limitations to the effectiveness of traditional pest management programmes. Since many, if not most, agricultural and urban pests and pests of other managed ecosystems are migratory (e.g. bollworms, aphids and leaf rust), considering the role of migration is essential for determining optimal AWPM strategies.
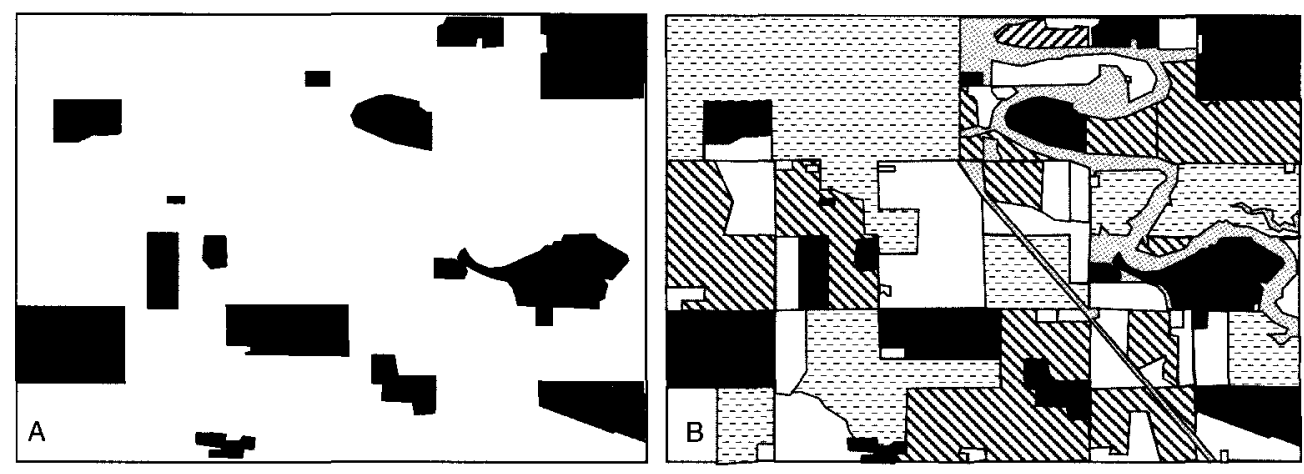

Fig. 2.1. Comparison of the (a) metapopulation and (b) landscape approaches to population ecology. 
What differentiates situations where the metapopulation concept is useful from those where an assumption of one large panmictic population is more applicable is whether the total population can be considered to be composed of discrete local breeding populations connected by migration (Hanski and Gilpin, 1997). More specifically, the pest insect's total population functions as a metapopulation when its hosts are distributed in discrete patches, subpopulations on the patches have a high probability of extinction, unoccupied patches are available to be colonized, and subpopulations do not fluctuate synchronously (Hanski and Gilpin, 1997). For many pest insects of agriculture, the first three criteria are satisfied. However, the fourth criterion is less certain, and in fact will often not be satisfied, because populations of many insects are highly dependent on climatic factors such as temperature, which are correlated over broad geographic areas.

Furthermore, the matrix is rarely without effect on population processes and can inhibit or accentuate movement of individuals among habitat patches, function as a conduit to channel movement in particular directions or serve as habitat for individuals or as a source of mortality to them (Forman, 1995). A landscape perspective that considers the composition and distribution of habitat and non-habitat patches may be insightful in designing AWPM programmes for some pests. In a landscape approach, the matrix is not considered uninhabitable, but consists of a heterogeneous mosaic of patches and other elements that interact with the species in complex ways (Fig. 2.1b). The main limitation of the landscape approach is lack of a comprehensive theoretical foundation, which limits the ability to make predictions based on well-understood theory and mathematical models (Hanski, 1998). However, this limitation does not necessarily reduce the value of the landscape approach for investigating and modelling the spatio-temporal dynamics of a particular pest species in a particular geographic setting.

\section{Landscape Ecology and AWPM}

The main difference betwcen the metapopulation and landscape approaches to population dynamics involves the role of the matrix in the dynamics of populations on patches. In the metapopulation approach the matrix is considered to be uninhabitable but consistent in its effects on the dynamics of populations on patches. In the landscape approach the matrix can have varying effects on local populations, which can be highly influential to within-patch dynamics (Hanski, 1998). Dunning et al. (1992) formalized terminology for landscape effects on biological populations by identifying four classes of important ecological effects of landscapes on local populations (i.e. populations in patches): landscape complementation, landscape supplementation, source-sink dynamics and neighbourhood effects. Taylor et al. (1993) added the idea of landscape connectivity to the four processes defined by Dunning et al. (1992).

Landscape complementation occurs when an organism requires two or more non-substitutable resources that are located in different patch types. The nonsubstitutable resources are required by the species for different reasons, and possibly at different times during its life. The organism has to move between patch types to obtain these resources. If the patch types occur in close proximity relative to the movement 
ability or behaviour of the organism, then a particular patch can support a larger population than if the patches are far enough apart that resources are difficult to obtain by cross-patch movement (see Fig. 2.2a). The presence of the resources in a particular habitat patch is complemented by the close proximity of the resources in the second patch, and larger populations can be supported in the area of proximity of the patches.

Landis and Haas (1992), in a study of the European corn borer parasitoid, Eriborus terebrans, demonstrated landscape complementation. Eriborus terebrans density was greater where maize fields were adjacent to woodlots than where maize fields were adjacent to agricultural fields. The woodlots were favourable habitat for adult survival by providing a food source for adults (flowering understorey plants); maize fields provide hosts for oviposition. Both resources are essential, and their availability in close proximity promotes large local populations of $E$. terebrans.

Landscape supplementation occurs when the population in a focal patch is increased because of the close proximity of other patches that contain the same resource or one that is used for the same function, making the resource easily accessible (see Fig. 2.2b). For Diabrotica species beetles (D. barberi, D. cristata and D. virgifera virgifera), supplementation occurs in Midwestern US agricultural landscapes. These beetles are closely tied to a primary habitat - maize or prairie, depending on species - but move to secondary habitat when the relative attractiveness of food sources in the primary habitat decreases. For these species, habitat type and contrast in pollination of plant species suitable as food for the beetles are important factors influencing habitat choice. Pollen availability in habitats adjacent to maize fields or prairie supplements the beetles. Extensive use of crop and non-crop habitats within the agricultural landscape suggests that an areawide approach, focusing on both crop and non-crop habitats, would be more effective for AWPM of corn rootworms than focusing only on maize fields (Campbell and Meinke, 2006).

Source-sink population dynamics occurs when productive 'source' patches, which have more births than deaths per generation, serve as sources of emigrants that
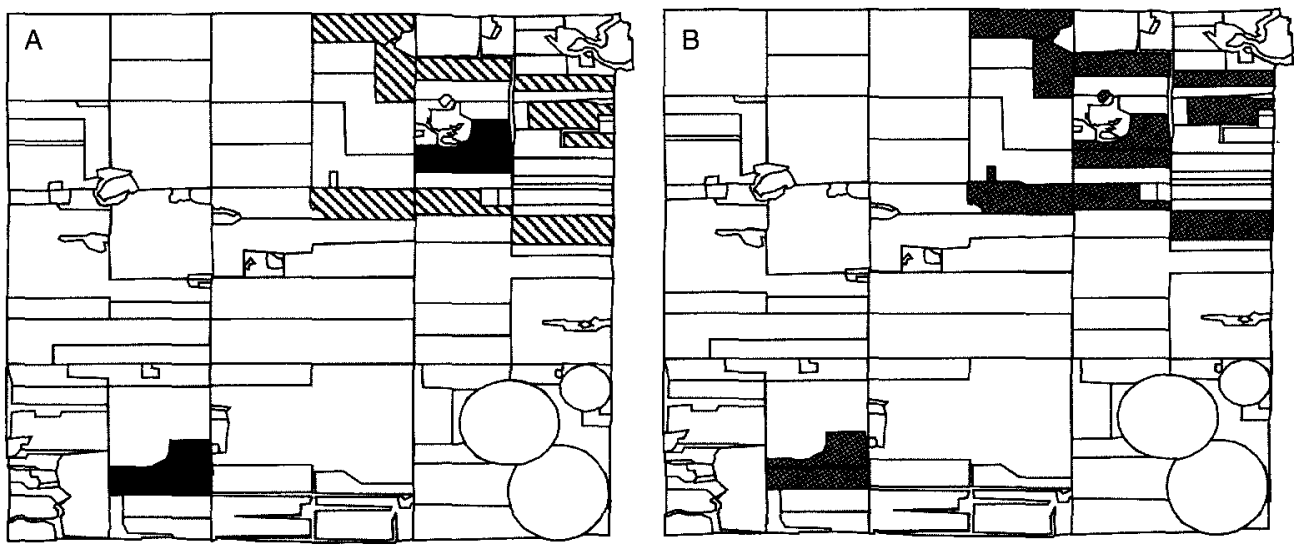

Fig. 2.2. Concepts of (a) landscape complementation and (b) supplementation in landscapes. The focal patch (in black) in the upper right area of figure (a) has a larger population than the focal patch in the lower left because of resources in nearby patches. Similarly for the corresponding patches in figure (b). 


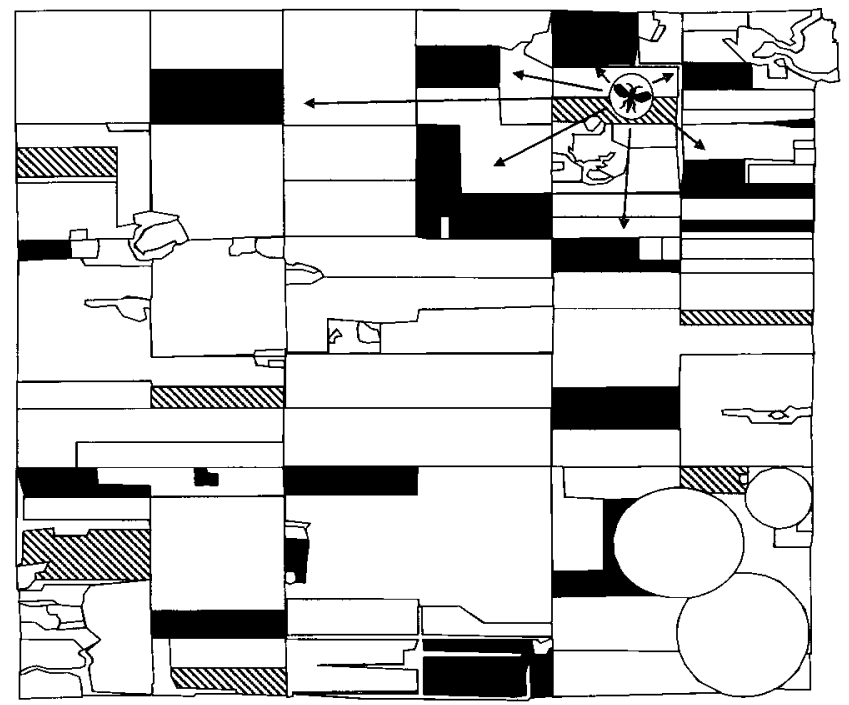

Fig. 2.3. A source/sink landscape. The source (cross-hatched) patches interact with sink (black) patches via dispersal.

migrate to less productive 'sink' patches (see Fig. 2.3). In sinks the death rate exceeds the birth rate (Pulliam, 1988; Pulliam and Danielson, 1991). Another class of patches exists, called pseudo-sinks, where the quality of the patch fluctuates between source and sink over time depending on population density, being source habitat at low density and sink habitat at high density (Watkinson and Sutherland, 1995). The concept of pseudo-sink can be extended to include habitats that fluctuate between source and sink on a seasonal basis irrespective of population density. Defined this way, the definition of pseudo-sink is useful for pest insects in agricultural settings that inhabit ephemeral habitats. The population size in a source-sink landscape can be strongly affected by the relative proportions of source and sink patches (Pulliam and Danielson, 1991).

For the Russian wheat aphid, the semi-arid landscapes of the High Plains Region of the USA can be conceptualized as a mosaic of source, sink, pseudo-sink and uninhabitable patches that changes over the course of the growing season (see Fig. 2.4). In order to maintain populations within an agricultural landscape the aphid must successfully exploit habitat patches when these are suitable and migrate to other suitable habitats when the current habitat declines in value. Both managed and unmanaged ecosystems are used. The quality of small grain fields as habitat for the Russian wheat aphid varies throughout the growing season. Patches of host cool- and warm-season grasses are sink habitat during most of the growing season, where mortality exceeds reproduction (Armstrong et al., 1991).

Patches of most other land use types are uninhabitable. Population persistence is dependent on migration among habitat patches, the quality of which vary spatially and temporally. Cool-season grasses are sink or pseudo-sink habitat for Russian wheat aphids, depending on species, but their existence in the landscape is critical to Russian wheat aphid survival during summer because they represent the only suitable resource available (Brewer et al., 2000). Russian wheat aphid survival over 

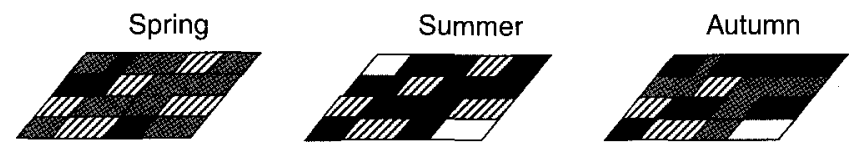

$$
\begin{aligned}
\square & =\text { source (volunteer wheat) } \\
\mathscr{Z} & =\text { source (wheat) } \\
\mathscr{Z} & =\text { sink/pseudo-sink (cool-season grasses) } \\
\boldsymbol{Z} & =\text { uninhabitable (non-host, dormant, fallow, etc.) }
\end{aligned}
$$

Fig. 2.4. Russian wheat aphid source/sink population dynamics in Great Plains, USA, agricultural landscapes.

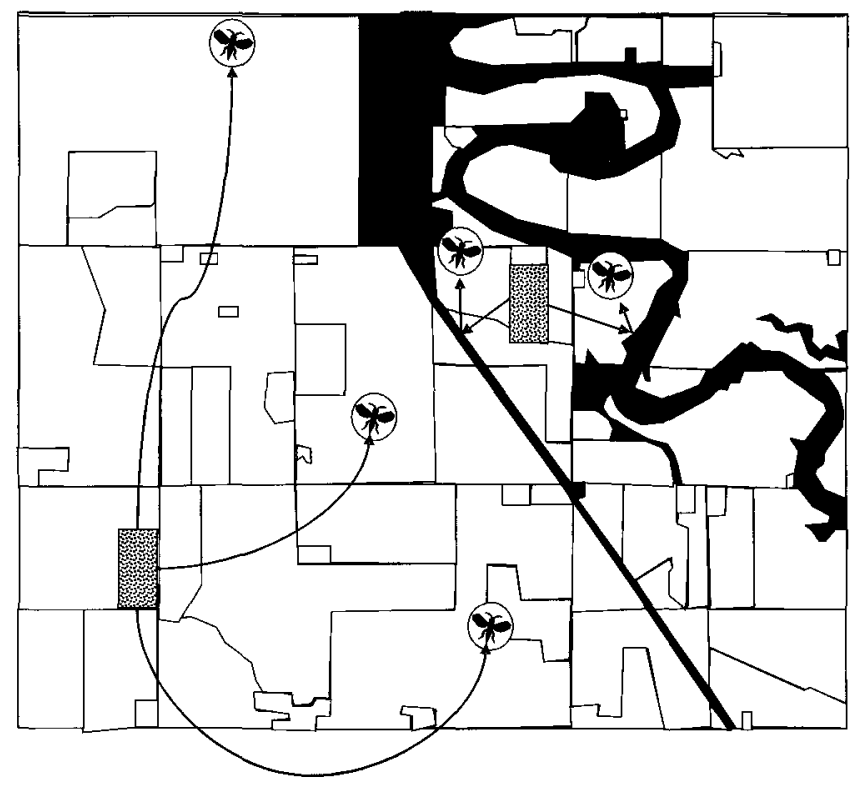

Fig. 2.5. Neighbourhood effects in landscapes; dispersal from the patch in the textured upper right area is restricted by the presence of boundaries that restrict inter-patch movement.

summer, in the absence of volunteer wheat, is therefore dependent on the extent and quality of sink and pseudo-sink habitat in the agricultural landscape. An AWPM programme for the Russian wheat aphid should be based on reducing the off-season hosts of the aphid, while simultaneously conserving natural enemies as key components (Giles et al., this volume, Chapter 19).

Neighbourhood effects occur when a species in a patch is more strongly affected by the pattern of the nearby landscape than by more distant aspects of pattern. The neighbourhood concept simply formalizes the idea that an organism's ability to utilize resources in adjacent patches within a landscape can be dependent on the nature of the boundaries between patches and the shape, size and composition of immediately surrounding patches (see Fig. 2.5) (Dunning et al., 1992). 
As an example of neighbourhood effects, Bach (1988) demonstrated that a tomato border around squash patches inhibited movement of squash bugs from the patch to nearby patches of squash. Thus, tomato acted as an impermeable or semi-permeable boundary for movement of squash bugs between habitat patches. Wratten et al. (2003) demonstrated, for certain Syrphidae species of agricultural landscapes in New Zealand, that field boundaries composed of poplar hedgerows impeded movement of the syrphid flies to and from agricultural fields more than did boundaries consisting of post-and-wire fences. This study suggests that boundary structure plays a role in the functioning of spatially heterogeneous syrphid populations in agricultural landscapes by inhibiting rates of recolonization of agricultural fields following disturbance, such as insecticide application. These neighbourhood effects could alter predator-prey interactions by delaying the numerical response of the syrphids to population increases of their aphid prey (Wratten et al., 2003).

Finally, connectivity, which is the degree to which the landscape facilitates or impedes movement by individuals of a species among resource patches, modifies the other landscape processes (see Fig. 2.6). Connectivity is a function of landscape structure (the composition and arrangement of elements in the landscape) and also the biology, behaviour and morphology of the particular organism (Taylor et al., 1993).

Tewksbury et al. (2002) demonstrated that increased connectivity resulting from construction of early successional corridors in forest resulted in greater exchange of insects between patches, and also increases in plant-insect interactions (pollination). Kruess and Tscharntke (2000) demonstrated that species richness of herbivorous insects on patches of bush vetch, Vicia sepium, increased with an increasing area of meadows that contained bush vetch, which suggests that the insects exhibit greater

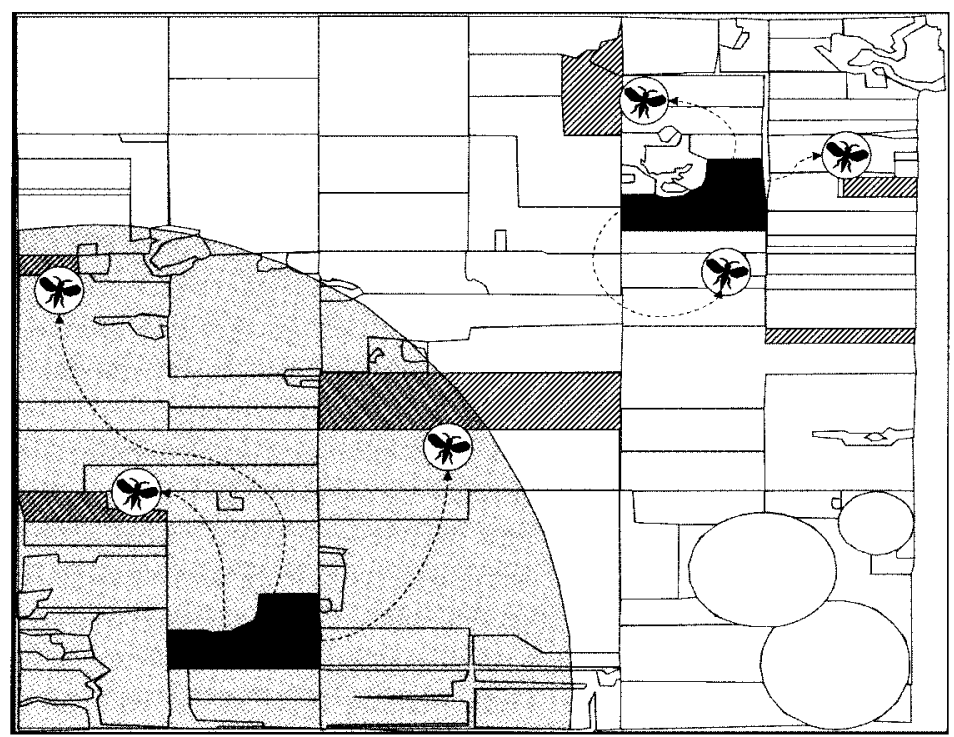

Fig. 2.6. Effects of varying connectivity (denoted by shading) on populations in heterogeneous landscapes; the high connectivity of the landscape matrix in the lower left area facilitates dispersal as compared with that in the upper right. 
dispersal and patch-finding ability in a matrix with high connectivity. Not unexpectedly, species diversity decreased with increasing patch isolation.

For many pest insects, agricultural landscapes present an ever-changing mosaic of patches that exhibit classes of effects such as those defined by Dunning et al. (1992) and Taylor et al. (1993). Thorough understanding of the nature of landscape interactions for pest species and their natural enemies may aid in optimizing AWPM programmes for particular pests. For example, if a total population, in the sense defined by Knipling, is structured into distinguishable subpopulations in source and sink habitat patches, then the population can be managed without treating the subpopulations uniformly. The metapopulation and landscape approaches suggest that synchronous treating of all source populations over several generations should control, if not eradicate, the pest. Patches with sink populations may be located in natural areas or in crops that can be damaged, however, so they cannot support population growth. Thus, AWPM from a landscape perspective may be able to save treatment and environmental costs by managing only source populations, with necessary connectivity to supplementing and complementary habitat.

Concepts from metapopulation and landscape ecology may be useful for describing the dynamics of Knipling's total population in future AWPM programmes for, at least, some pest insects, and therefore may aid in developing effective AWPM strategies. Spatially explicit models are an important tool for studying populations in heterogeneous landscapes and for developing and assessing strategies and tactics for control in complex spatial systems where effects of system structure and inputs on dynamics are not always obvious. In fact, Knipling used modelling extensively in his analyses of the AWPM concept (Knipling, 1979, 1992), although the models did not explicitly consider spatial distribution. Next, we discuss the role of models and related tools in AWPM.

\section{Ecological Modelling}

How can scientists optimize the economics and efficacy of an AWPM plan given all the practical hurdles that need to be overcome? We believe that ecological theory and case studies based on modelling can help find very good, if not optimal, solutions. Modelling and theory should go hand-in-hand to help answer questions on management approaches. For example, we could ask how synchronous and how uniform management of a pest should be? Would $100 \%$ mortality on $90 \%$ of the cropland accomplish the same goal as $90 \%$ mortality on every hectare? Or $100 \%$ mortality on all cropland in $90 \%$ of the pest's generations over several years? What if the pest's phenology, genetic structure and spatial distribution vary from year to year? Models can help us explore the temporal and spatial dynamics of pests targeted by AWPM programmes.

In this section, we discuss the contribution of spatially explicit models and other tools to understanding and implementing AWPM. As with all technologies, such tools have limitations. For example, sometimes models are too specific to a particular pest or ecosystem to provide general assistance. In other cases, general models omit certain processes or conditions, thus limiting their ability for making specific recommendations. By considering a variety of approaches, we hope to derive valuable insights in 
developing management plans, as well as to learn what additional work may be important to further optimize the management plan.

Carrière et al. (2006) used GIS to account for the effects of agroecosystem heterogeneity on dispersal and population dynamics. The results of their model allowed them to develop recommendations for AWPM that included the placement of cropland and fallow fields for better control of a regional pest. Brewster and Allen (1997) integrated a model that simulated the temporal and spatial dynamics of a pest with a digital map of heterogeneously distributed habitat. Their approach could be used to evaluate the effect of management tactics such as biological control on pests that infest multiple habitats.

Bessin et al. (1991) used a simulation model that considered control by host plant resistance and predation to study AWPM of Diatraea saccharalis. They concluded that mixtures of resistant and susceptible sugarcane deployed over broad geographic scales would help control the pest. However, their results were sensitive to assumptions about adult dispersal. El-Sayed et al. (2006) reviewed the literature on empirical and modelling studies of mass trapping and drew several conclusions. They emphasized the value of targeting low-density, isolated populations. In addition, mass trapping was most successful or more cost-effective for monophagous, univoltine pests with lower population growth rates over a given unit of time.

In a very interesting analysis, Byers and Castle (2005) explored the question: can the traditional pest management decision to treat individual fields asynchronously at a specified population threshold be improved by synchronously treating all fields at an average population threshold in an areawide programme? They developed a simulation model of insect populations in a large set of fields that varied in exponential growth each day of a season. A portion of the insects also dispersed to adjacent fields at each time step. Byers and Castle (2005) considered a landscape with explicit spatial structure, with distances between patches determining dispersal probabilities.

In one model, populations in each field were monitored. A field was treated with insecticide if the population exceeded a threshold (asynchronous model), as performed in traditional IPM. A second model treated the entire array of fields with insecticide when the average population of all fields exceeded the same threshold (synchronous model). Byers and Castle (2005) found that the synchronous model, at all growth and dispersal rates tested, had average field populations during a season that were significantly lower (see Fig. 2.7) and required fewer treatments than the asynchronous method. Byers and Castle (2005) concluded that cooperation among growers in areawide monitoring of fields to obtain an average population estimate for use with treatment thresholds would result in significantly less insect damage and fewer insecticide treatments.

However, their conclusions may be valid for only a small portion of real situations that are likely to be encountered by farmers and their advisors. Byers and Castle (2005) allowed growth in the population at each site during each time step. This implies that each time step is a significant portion of one generation: therefore, the results are valid only for pests with overlapping generations. They also focused on pests that require control at low densities, which means that they did not incorporate density-dependent dispersal, density-dependent survival and regulation by natural enemies. Byers and Castle (2005) essentially modelled a system in which the growth of the total population is highly predictable over time. In the future, interesting extensions of the model could include variability in population growth rate over time, asynchrony in phenology of 


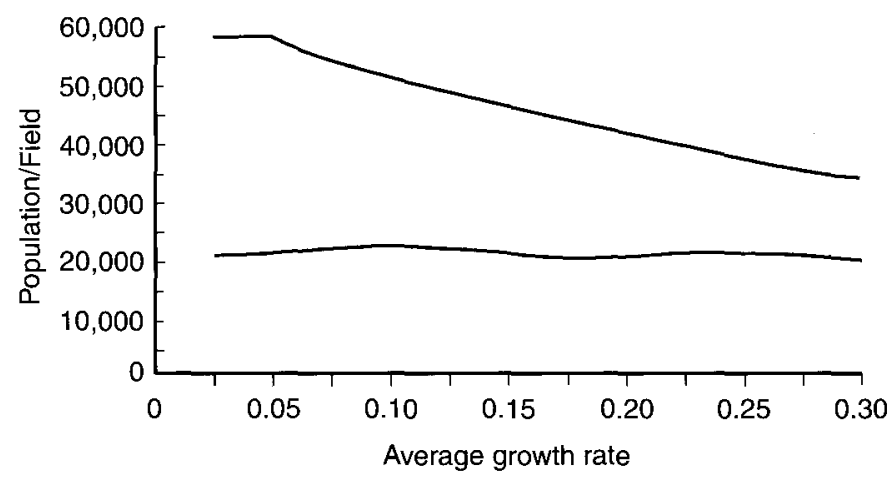

Fig. 2.7. Relationship between mean population growth rate and mean pest insect population per field per day (redrawn from Byers and Castle, 2005). The growth rate is the intrinsic rate of population increase, which is a dimensionless number; it is the natural logarithm of the ratio of population sizes at two different times.

vulnerable life stages across the landscape, sampling costs and evolution of insecticide resistance. It is possible that, with greater temporal uncertainty and temporal asynchrony, an asynchronous management strategy would be better than the synchronized areawide effort conceptualized by Byers and Castle (2005).

\section{Theory of Host-density Thresholds}

If biological control by a parasite is directed at a total population, then the concept of host-density thresholds must be considered when AWPM goals and tactics are being developed. Eradication by a host-specific parasitoid or pathogen may not be feasible for ecological reasons. Even long-term management may be difficult depending on how low the density of the targeted pest must be driven in comparison with the searching and reproductive abilities of the natural enemy in heterogeneous landscapes (Onstad and Kornkven, 1999). In the epidemiological literature (Onstad and Carruthers, 1990; Onstad, 1993; Onstad and McManus, 1996), it is generally accepted that, for a host-specific pathogen used in classical biological control, the pathogen will be extirpated at low host densities before the host is extirpated. Essentially, without continuous, multi-generation inundative releases of parasites, the parasites will drive the host density so low that the parasite will be unable to find and attack the remaining susceptible pests. This also means that efforts to use biological control in natural areas where lower densities of a pest may occur will need to compensate for the lower encounter rates between host and parasite. Furthermore, AWPM may have to rely on non-classical biological control to achieve its goals.

\section{Insect Resistance Management}

Insect resistance management can be very similar to AWPM because both depend on coordination of efforts over large regions (Onstad, 2007). Siegfried et al. (1998) 
recognized the relationship between AWPM and insect resistance management when they warned proponents of AWPM about the increased risk of resistance evolution if areawide projects treat the landscape uniformly. They believed that some attributes of AWPM are incompatible with many conventional insect resistance management (IRM) techniques, but suggested that use of biologically based control tactics, such as behaviour-disrupting chemicals, may contribute to both AWPM and insect resistance management.

Onstad and Guse (1999) showed clearly that a regional pest population could be eradicated, if not maintained at very low levels, by the use of highly effective transgenic insecticidal crops. This was the case even when $10-30 \%$ of the landscape was planted with refugia of non-insecticidal plants. Carrière et al. (2003) described a real case of suppression of a regional pest using a transgenic insecticidal crop. Peck and Ellner (1997) and Peck et al. (1999) used spatially explict models to explore insect resistance management of a regional pest. Their conclusions were that the population growth rates and dispersal rates determine the likelihood of success of management, which are likewise relevant to AWPM over the long term.

\section{Monitoring}

How should monitoring be incorporated into an AWPM plan? Monitoring is costly and should not be performed unless absolutely necessary in AWPM. Under ideal conditions monitoring should not be performed - except following several years of synchronized, uniform control - to determine the success of the project. Certainly, monitoring should be performed at the end of the project's time horizon. In theory, one of the economic savings in AWPM is the elimination of monitoring costs in a strategy that simply inundates the environment with treatments targeting the pest on a schedule and in all areas expected to be infested. However, in practice, monitoring will probably occur. Therefore, how can ecological theory help select times and locations for monitoring?

One approach in AWPM is to trade treatments, and their cost for monitoring and its costs. In other words, use monitoring to decide when and where to treat the population to improve regional control. In situations involving metapopulations, monitoring could be used to determine the locations of source and sink patches. Then only the source subpopulations would be treated over time while sink patches were monitored to determine whether they functioned as refugia for the pest from which to recolonize source patches.

In any scenario in which the pest population density is highly variable over space and time, particularly with large areas or long periods without significant pest densities, it is possible that treatments could be optimized in their efficacy by monitoring and then treating the pest either under only low-density situations or high densities. The cotton boll weevil eradication programme in the southern USA exemplifies this approach. Monitoring is an essential component of the eradication programme, because pheromone traps are used to determine those fields to be treated with low doses of the broad-spectrum insecticide malathion. Insecticide application directed at infested fields, combined with cultural practices applied to all fields, has been 
successful in reducing the boll weevil to undetectable levels (Allen, this volume, Chapter 20).

Some pests may be more easily eradicated or maintained at very low densities if the management begins at low densities. This is true for mass trapping techniques (El-Sayed et al., 2006). But for other pests, density at time of treatment may be irrelevant, or tactics such as biological control may be more effective at initially high densities. For example, AWPM of the Russian wheat aphid is based almost completely on preventive tactics, including conservation biological control, and density at time of implementation of AWPM is not important for this species (Giles et al., Chapter 19, this volume).

Highly variable pests may not be good targets for AWPM, because monitoring of these pests (which often exist at densities below economic thresholds) is so important and control is not needed as often as for other pests. We are not capable of providing in this chapter the comprehensive discussion that the subject of monitoring deserves. Certainly, any AWPM programme that plans to use monitoring must start with an understanding of: (i) the pest's population dynamics in various habitats (Park and Tollefson, 2005); (ii) the increasing difficulty in sampling as the management programme progresses (Venette et al., 2002); and (iii) the costs of extensive and intensive sampling (Nyrop et al., 1986).

\section{Conclusion}

AWPM programmes, including eradication programmes, have provided some outstanding successes both in cost effectiveness and in the level and durability of control. Successful programmes were based on detailed knowledge of the biology of the target pest and on proven technologies for suppressing its populations. While some programmes have been highly successful, there are opportunities to refine approaches through the application of ecological concepts and technology, which could make AWPM applicable to a broader range of pest species and make it more economical in terms of money and time. Recent advances in ecology, particularly from the fields of metapopulation and landscape ecology, are applicable for the study of candidate species for AWPM. Application of ecological concepts, particularly when complemented by modelling and other supporting technologies, could help in defining the spatial limits of the total population from an operational viewpoint, and in optimizing AWPM programmes.

\section{Acknowledgement}

We thank Tim Johnson for producing the illustrations used in this manuscript. The views expressed herein are those of the authors only and do not necessarily reflect or represent the opinions, positions or policies of the US Department of Agriculture. 


\section{References}

Addicott, J.F., Aho, J.M., Antolin, M.F., Padilla, D.K., Richardson, J.S. and Soluk, D.A. (1987) Ecological neighborhoods: scaling environmental patterns. Oikos 49, 340-346.

Allen, T.F.H. and Starr, T.B. (1982) Hierarchy: Perspectives for Ecological Complexily. University of Chicago Press, Chicago, Illinois.

Armstrong, J.S., Porter, M.R. and Peairs, F.B. (1991) Alternate hosts of the Russian wheat aphid (Homoptera: Aphididae) in northeastern Colorado. Joumal of Economic Entomology $84,1691-1694$.

Bach, C. (1988) Effects of host patch size on herbivore density: underlying mechanisms. Ecology $69,1103-1117$.

Bessin, R.T., Stinner, R.E. and Reagan, T.E. (1991) Modeling the area-wide impact of sugarcane varieties and predation on sugarcane borer (Lepidoptera: Pyralidae) populations in southern Louisiana. Environmental Entomology 20, 252-257.

Brewer, M.J., Donahue, J.D. and Burd, J.D. (2000) Seasonal abundance of Russian wheat aphid (Homoptera: Aphididae) on non-cultivated perennial grasses. Foumal of the Kansas Entomological Society 73, 85--95.

Brewster, C.C. and Allen, J.C. (1997) Spatiotemporal model for studying insect dynamics in large-scale cropping systems. Environmental Entomology 26, 473-482.

Byers, J.A. and Castle, S.J. (2005) Areawide models comparing synchronous versus asynchronous treatments for control of dispersing insect pests. Foumal of Economic Entomology 98, $1763-1773$.

Calkins, C.O. and Faust, R.J. (2003) Overview of areawide programs and the program for suppression of codling moth in the western USA directed by the United States Department of Agriculture-Agricultural Research Service. Pest Management Science 59, 601-604.

Campbell, L.A. and Meinke, L.J. (2006) Seasonality and adult habitat use by four Diabrotica species at prairie-corn interfaces. Environmental Entomology 35, 922-936.

Carrière, Y., Ellers-Kirk, G., Sisterson, M., Antilla, L., Whitlow, M., Dennehy, T.J. and Tabashnik, B.E. (2003) Long-term regional suppression of pink bollworm by Bacillus thuringiensis cotton. Proceedings of the National Academy of Science USA 100, 1519-1523.

Carrière, Y., Ellsworth, P.G., Dutilleul, P., Ellers-Kirk, G., Barkley, V. and Antilla, L. (2006) A GIS-based approach for areawide pest management: the scales of Lygus hesperus movements to cotton from alfalfa, weeds, and cotton. Entomologia Experimentalis et Applicata 118, 203-210.

Drake, V.A. and Gatehouse, A.G. (1994) Insect Migration: Tracking Resources Through Space and Time. Cambridge University Press, Cambridge, UK.

Dunning, J.B., Danielson, B.J. and Pulliam, H.R. (1992) Ecological processes that affect populations in complex landscapes. Oikos 65, 169-175.

El-Sayed, A.M., Suckling, D.M., Wearing, C.H. and Byers, J.A. (2006) Potential of mass trapping for long-term pest management and eradication on invasive species. Fournal of Economic Entomology 99, 1550-1564.

Forman, R.T.T. (1995) Land Mosaics: the Ecology of Landscapes and Regions. Cambridge University Press, Cambridge, UK.

Hanski, I.A. (1998) Metapopulation dynamics. Nature 396, 41-49.

Hanski, I.A. and Gilpin, M.E. (1997) Metapopulation Biology: Ecology, Genetics, and Evolution. Academic Press, New York.

Klassen, W. (2000) Area-wide approaches to insect pest management: history and lessons. In: Tan, K. (ed.) Area-wide Control of Fruit Flies and Other Insect Pests. Penerbit Universiti Sains, Penang, Malaysia, pp. 21-38.

Klassen, W. (2003) Edward F. Knipling: titan and driving force in ecologically selective area-wide pest management. Fournal of the American Mosquito Control Association 19, 94-103. 
Knipling, E.F. (1979) The Basic Principles of Insect Population Suppression and Management. Agricultural Handbook 512, United States Department of Agriculture, Washington, DC.

Knipling, E.F. (1992) Principles of Insect Parasitism Analyzed from new Perspectives: Practical Implications for Regulating Insect Populations by Biological Means. Agricultural Handbook 693, United States Department of Agriculture, Washington, DC.

Kruess, A. and Tscharntke, T. (2000) Species richness and parasitism in a fragmented landscape: experiments and field studies with insects on Vicia sepium. Oecologia 122, 129-137.

Landis, D.A. and Haas, M.J. (1992) Influence of landscape structure on abundance and within field distribution of European corn borer (Lepidoptera: Pyralidae) larval parasitoids in Michigan. Environmental Entomology 21, 409-416.

Levandowsky, M. and White, B.S. (1977) Randomness, time scales, and the evolution of biological communities. Evolutionary Biology 10, 69-161.

Levins, R. (1969) Some demographic and genetic consequences of environmental heterogeneity for biological control. Bulletin of the Entomological Society of America 15, 237-240.

Linquist, D.A. (2000) Pest management strategies: area-wide and conventional. In: Tan, K. (ed.) Area-wide Control of Fruit Flies and Other Insect Pests. Penerbit Universiti Sains, Penang, Malaysia, pp. 13-19.

Loehle, C. (1987) Hypothesis testing in ecology: psychological aspects and the importance of theory maturation. Quarterly Review of Biology 62, 397-409.

Metcalf, R.L. (1991) Insects - man's chief competitors. In: Menn, J.J. and Steinhauer, A.L. (eds) Progress and Perspectives for the 21 st century. Centenial National Symposium, Entomological Society of America, Lanham, Maryland.

Metcalf, R.L. and Luckman, W.H. (1975) Introduction to Insect Pest Management. John Wiley \& Sons, New York.

Murphy, D.D., Freas, K.E. and Weiss, S.B. (1990) An environment-metapopulation approach to population viability analysis for a threatened invertebrate. Conservation Biology 4, 41-51.

Nyrop, J.P., Foster, R.E. and Onstad, D.W. (1986) The value of sample information in pest control decision making. Fournal of Economic Entomology 79, 1421-1429.

O'Neill, R.V., DeAngelis, D.L., Waide, J.B. and Allen, T.F.H. (1986) A Hierarchical Concept of Ecosystems. Princeton University Press, Princeton, New Jersey.

Onstad, D.W. (1992) Temporal and spatial scales in epidemiological concepts. Fournal of Theoretical Biology 158, 495-515.

Onstad, D.W. (1993) Thresholds and density dependence: the roles of pathogen and insect densities in disease dynamics. Biological Control 3, 353-356.

Onstad, D.W. (2007) Insect Resistance Management: Biology, Economics, and Prediction. Academic Press, New York.

Onstad, D.W. and Carruthers, R.I. (1990) Epizootiological models of insect diseases. Annual Review of Entomology 35, 399-419.

Onstad, D.W. and Guse, C.A. (1999) Economic analysis of transgenic maize and nontransgenic refuges for managing European corn borer (Lepidoptera: Pyralidae). Foumal of Economic Entomology 92, 1256-1265.

Onstad, D.W. and Kornkven, E.A. (1999) Persistence of natural enemies of weeds and insect pests in heterogeneous environments. Chapter 19. In: Hawkins, B.A. and Cornell, H.V. (eds) Theoretical Approaches to Biological Control. Chapman and Hall, London, pp. 349-367.

Onstad, D.W. and McManus, M.L. (1996) Risks of host-range expansion by insect-parasitic biocontrol agents. BioScience 46, 430-435.

Park, Y.-L. and Tollefson, J.J. (2005) Spatial prediction of corn rootworm (Coleoptera: Chrysomelidae) adult emergence in Iowa cornfields. Foumal of Economic Entomology 98, 121-128.

Peck, S.L. and Ellner, S.P. (1997) The effect of economic thresholds and life-history parameters on the evolution of pesticide resistance in a regional setting. American Naturalist 149, $43-63$. 
Peck, S.L., Gould, F. and Ellner, S.P. (1999) Spread of resistance in spatially extended regions of transgenic cotton: implications for management of Heliothis virescens (Lepidoptera: Noctuidae). Joumal of Economic Entomology 92, 1-16.

Peters, R.H. (1988) Some general problems for ecology illustrated by food web theory. Ecology $69,1673-1676$.

Pickett, S.T.A. and Gadenasso, M.L. (1995) Landscape ecology: spatial heterogeneity in ecological systems. Science 269, 331-334.

Pulliam, H.R. (1988) Sources, sinks, and population regulation. American Naturalist 132, 652-661.

Pulliam, H.R. and Danielson, B.J. (1991) Sources, sinks, and population regulation: a landscape perspective on population dynamics. American Naturalist 137, 550-566.

Roughgarden, J., May, R.M. and Levin, S.A. (1989). Perspectives in Ecological Theory. Princeton University Press, Princeton, New Jersey.

Schneider, J.C. (1989) Role of movement in evaluation of area-wide insect pest management tactics. Environmental Entomology 18, 868-874.

Siegfried, B.D., Meinke, L.J. and Scharf, M.E. (1998) Resistance management concerns for areawide management programs. Fournal of Agricultural Entomology 15, 359-369.

Tan, K. (2000) Area-zide Control of Fruit Flies and Other Insect Pests. Penerbit Universiti Sains, Penang, Malaysia.

Taylor, P.D., Fahrig, L., Henein, K. and Merriam, G. (1993) Connectivity is a vital element of landscape structure. Oikos 68, 571-573.

Tewksbury, J.J., Levey, D.J., Haddad, N.M., Sargent, S., Orrock, J.L., Weldon, A., Danielson, B.J., Brinkerhoff, J., Damschen, E.I. and Townsend, P. (2002) Corridors affect plants, animals, and their interactions in fragmented landscapes. Proceedings of the National Academy of Sciences, USA 99, 12923-12926.

Venette, R.C., Moon, R.D. and Hutchison, W.D. (2002) Strategies and statistics of sampling for rare individuals. Annual Review of Entomology 47, 143-174.

Watkinson, A.R. and Sutherland, W.J. (1995) Sources, sinks, and pseudo-sinks. Journal of Animal Ecology 64, 126-130.

Weins, J.A. (1976) Population responses to patchy environments. Annual Reviewe of Ecology and Systematics 7, 81-120.

Weins, J.A. (1989) Spatial scaling in ecology. Functional Ecology 3, 385-397.

Wratten, S.D., Bowie, M.H., Hickman, J.M., Evans, A.M., Sedcole, J.R. and Tylianakis, J.M. (2003) Field boundaries as barriers to movement of hover flies (Diptera: Syrphidae) in cultivated land. Oecologia 134, 605-611. 